\title{
LA TRANSFERENCIA DE PROPIEDAD DE LOS BIENES MUEBLES INCORPORALES EN EL CODIGO CIVIL
}

Miguel Torres Méndez

\section{PLANTEAMIENTO DEL PROBLEMA}

En el título de la propiedad, en el sub-capítulo referente a la transmisión de la propiedad, el artículo 947 del Código Civil establece que la transferencia de propiedad de una cosa mueble determinada se efectúa con la tradición a su acreedor, salvo disposición legal diferente.

Se trata de la regla de transferencia de propiedad aplicable al caso de bienes muebles corporales, o como propiamente prescribe el citado artículo: "cosa mueble".

Como se sabe, dentro del género o concepto de "bien" se distinguen a su vez dos categorías o especies del mismo, que son: bienes corporales o "cosas" y bienes incorporales o "derechos". La diferencia estriba lógicamente en que los primeros, las cosas, tienen una corporeidad o materialidad que les da una tangibilidad concreta; mientras que los segundos, los derechos, carecen por completo de corporeidad, por lo que no son, pues, materiales ni tangibles.

Raymundo Salvat explica bien esta diferencia de la siguiente manera: "Al definir el dominio, el Código Civil nos dice que este derecho recae sobre objetos materiales (art. 2506); pero como lo hemos dicho anteriormente, existe también una serie de propiedades de un carácter especial, que recaen, no sobre objetos materiales, sino sobre creaciones del espíritu o de la inteligencia del hombre. Son las siguientes: $1^{\circ}$ la propiedad de las obras científicas, literarias y artísticas; $2^{\circ}$ la propiedad de los inventos; $3^{\circ}$ la propiedad de las marcas; $4^{\circ}$ la propiedad de los dibujos o modelos industriales, materia que en 
nuestro derecho no ha sido especialmente reglamentada. Todas estas propiedades recaen sobre objetos diferentes, pero presentan un rasgo común: recaen sobre algo inmaterial o incorporal, porque este objeto no es el libro o la obra producida, el invento, la marca o el establecimiento, sino la creación, el trabajo que ellos representan" (1).

Jack Bigio Chrem hace lo mismo al explicar qué tipo de bienes pueden venderse: "Con arreglo al artículo 1529 del Código Civil de 1984 pueden venderse no sólo las cosas materiales, sino también, los derechos incorporales. Ello se desprende de la sustitución del vocablo "cosa" empleado en el artículo 1383 del Código Civil derogado, por el término "bien", que tiene mayor alcance, y que es utilizado en el artículo 1529 del nuevo texto civil" (2).

Así, son bienes corporales, por ejemplo, son cosas, un automóvil, una casa, un vestido. Es claro apreciar en ellos que gozan de corporeidad o materialidad y por ende son tangibles. Por el contrario, son bienes incorporales, son derechos, los derechos de autor, de inventor, de patentes, las marcas. Es claro también apreciar en ellos que no gozan de corporeidad o materialidad, por lo que no pueden ser, pues, tangibles.

El artículo 947 del Código Civil no ofrece, pues, dificultad alguna, por cuanto tratándose de bien mueble corporal o "cosa mueble", como acertadamente prescribe la norma, no habrá problema en aplicar este modo de transferencia de propiedad consistente en la "tradición".

El problema se presenta para los bienes muebles incorporales, dado que es evidente que es imposible aplicar para ellos la tradición o entrega debido a su incorporeidad. ¿Cuál será el régimen de transferencia de propiedad entonces para este tipo de bienes muebles?

(1) SAlVAT, Raymundo. Tratado de Derecho Civil Argentino. Tomo I, Buenos Aires 1927, p. 629.

(2) BIGIO CHREM, Jack. La Compraventa y la Trasmisión de Propiedad. En: Para Leer el Código Civil, Tomo I. Lima 1984, pp. 200 y 201. 
El objeto del presente trabajo consiste en hallar una solución adecuada al problema planteado.

\section{POSIBLE REGIMEN DE TRANSFERENCIA DE PROPIEDAD}

La solución al problema planteado no puede consistir en otra cosa que en hallar el posible régimen de transferencia de propiedad aplicable a este tipo de bienes. Esto en vista de que el vigente Código Civil ha omitido regular dicho régimen. Tal como se ha podido apreciar, en el sub-capítulo relativo a la trasmisión de la propiedad el Código Civil sólo se ocupa de regular el régimen de transferencia de propiedad de las cosas, no existiendo norma alguna en dicho Código que regule dicho régimen para los derechos.

La determinación del régimen de transferencia de propiedad aplicable a estos bienes es de singular importancia, debido a que es obvio darse cuenta que de alguna manera debe operarse esta transferencia. Por supuesto que ante este vacío legal el transferente y adquirente de un derecho o mueble incorporal pueden pactar o establecer el régimen que deseen o juzguen conveniente, caso en el cual, pues, no habrá ningún problema. Pero el problema precisamente se presenta en el caso en que las partes no hayan establecido régimen alguno, sino que simplemente se han limitado a celebrar el título dispositivo correspondiente. En este último caso, es pues indispensable saber o determinar de qué manera se va a transferir el derecho de propiedad. ¿De qué manera el adquirente va a exigirle al transferente que le transfiera la propiedad del derecho o mueble incorporal sobre el cual han contratado? O, lo que es lo mismo, ¿de qué manera el transferente debe cumplir con la transferencia de propiedad de ese bien?

La determinación del régimen de transferencia de propiedad para este tipo de bienes es, pues, de radical importancia, porque de no hallarse dicho régimen sencillamente la propiedad de los mismos no podrá transferirse.

Se sabe asimismo que el vigente Código Civil peruano ha adoptado para la transferencia de propiedad el Régimen del Título y el Modo. Este régimen consiste en que la transferencia de propiedad se da a través de dos actos: el título y el modo. 
Es Raymundo Salvat quien define didácticamente ambas instituciones de la siguiente manera: "..., hay que distinguir el modo y el título: el primero sería el hecho o acto que da nacimiento a la adquisición; el segundo sería el acto jurídico que algunas veces se encuentra como antecedente del hecho 0 acto de adquisición" (3).

Fernando López de Zavalia modernamente complementa estas definiciones de la siguiente manera: "... título, es decir acto que por sí solo no transmite el dominio, pero que sirve mediatamente para ello, al explicar y justificar el modo, dándole su razón de ser" (4). Para luego seguir afirmando: "El modo, es en cambio, el acto que sirve inmediatamente para la transmisión del dominio" (5).

En este régimen se distingue, en consecuencia, el título de adquisición y el modo de adquirir, de tal manera que sólo reunidos el título y el modo se adquiere el derecho de propiedad.

Este ha sido el régimen que ha adoptado el vigente Código Civil al establecer en el artículo 947 que la adquisición de la propiedad de las cosas muebles se perfecciona con la tradición; y la de los inmuebles, por aplicación del artículo 949, por la obligación de transferir (el título), que cobra efecto traslativo (el modo).

Esta situación puede llevar a pensar que como el Código Civil adopta el Régimen del Título y el Modo sólo para las cosas o muebles corporales, para los derechos o muebles incorporales necesariamente, entonces, se tiene que aplicar un régimen de transferencia de propiedad distinto. Tal hipótesis llevaría a concluir, en consecuencia, que el régimen de transferencia de propiedad de estos bienes no es otro que el consensualista; esto en virtud de que para dicha transferencia sólo existen dos regímenes: el materialista y el consensualista. De tal manera que, por descarte, si no le es aplicable el régimen

(3) SALVAT, Raymundo, op.cit., Tomo I, p. 391.

(4) LOPEZ DE ZAVALIA, Fernando. Teoría de los Contratos. Tomo 2, Buenos Aires 1985, p. 28.

(5) Ibidem. 
materialista, en consecuencia, el único que le es aplicable es el consensualista.

El régimen materialista no es otro que el Régimen del Título y el Modo, que ya se ha explicado. El régimen consensualista, por el contrario, consiste simplemente en que la propiedad se transfiere por el solo acuerdo o consentimiento de las partes, sin requerirse de otro acto adicional. Legislaciones civiles como la francesa, italiana y portuguesa adoptan este régimen consensualista, al que también se le conoce con el nombre de "espiritualista".

Se debe aclarar que no es exacto afirmar que en el régimen consensualista título y modo se confundan o sean lo mismo, con lo que se daría a entender que este régimen forma parte del régimen del título y el modo, lo cual, pues, no es correcto. Así, Jack Bigio Chrem incurre en esta situación al explicar el sistema consensualista adoptado por el Código Civil Francés: "En la legislación francesa, que acepta la trasmisión de la propiedad por la sola fuerza de las convenciones, esta distinción, al menos en las relaciones entre las partes contratantes, carece de interés y aplicación práctica: el modo y el título se confunden; la venta, la donación y la permuta, son a la vez el uno y el otro" (6).

En el régimen consensualista no hay título y modo que se confundan,porque en él no es necesario que se den dos actos para que opere la transferencia de propiedad, como ocurre en el Régimen del Título y el Modo; la propiedad se transfiere mediante un solo acto: el acuerdo de voluntades.

Ahora bien, se debe señalar que no resulta correcta la tesis según la cual, por descarte, el régimen de transferencia de propiedad aplicables a los muebles incorporales sea el consensualista. Esto porque, como se sabe, en el vigente Código Civil peruano los contratos de enajenación no son traslativos de dominio, sino meramente obligacionales. Es decir, la compraventa, permuta, donación y mutuo no son suficientes, como acuerdo de voluntades o contrato, para transferir el derecho de propiedad. Estos contratos, lo único que generan o crean es la obligación de transferir el derecho de propie-

(6) BIGIO CHREM, Jack. Op.cit., p. 200. 
dad, mas no lo transfieren por sí mismos (artículos 1529, 1602, 1621 y 1648 , respectivamente).

Por lo tanto, estos contratos sólo son el título para adquirir y será necesario entonces de otro acto para que opere la transferencia de propiedad, el cual no puede ser otro que el modo de adquisición, es decir, el modo con el cual finalmente operará dicha transfeencia. El régimen de transferencia de propiedad aplicable a los muebles incorporales no puede ser otro, pues, que el Régimen del Título y el Modo y no el régimen consensualista.

Se debe interpretar, en consecuencia, el término "cosa" utilizado por el artículo 947 del Código Civil, en sentido amplio y lato, y considerar que la norma se refiere con dicho término al "bien" en general; con lo cual están contemplados dentro de esta norma tanto los muebles corporales como los incorporales.

Esta situación podría llevar a pensar igualmente que la tradición o entrega dispuesta como modo por el artículo 947 es, pues, sólo aplicable, por su naturaleza, a los muebles corporales; y que, por lo tanto, será la legislación especial la que establezca el modo para los muebles incorporales. Esto debido a que la citada norma establece como salvedad o excepción lo que disponga una norma legal distinga, al prescribir textualmente: "..., salvo disposición legal diferente". Y también, a que los muebles incorporales son derechos para los cuales, por carecer precisamente de corporeidad, existen registros especiales en los cuales se publicita adecuadamente su titularidad.

De esta manera, podría pensarse entonces que la legislación especial que existe sobre marcas o patentes, por ejemplo, dispone que el modo por el cual se adquiere el derecho de propiedad sobre ellos es la inscripción en el registro correspondiente; con lo cual no habría problema alguno para la transferencia de propiedad de este tipo de bienes.

Esta hipótesis cobra cierta relevancia al prescribir el Código Civil en el artículo 884 que las propiedades incorporales se rigen por su legislación especial.

Sin embargo, se debe señalar que no existe norma alguna en la legislación especial correspondiente a estos bienes que disponga 0 164 
establezca que la propiedad sobre los mismos se adquirirá con la inscripción. Lo único que regula esta legislación especial es la forma en que debe realizarse la inscripción. Dicha inscripción, en consecuencia, no es constitutiva; sino meramente para fines publicitarios. Por tanto, al no pronunciarse la legislación especial sobre el modo aplicable, es la tradición o entrega dispuesta por el citado artículo 947 del Código Civil, el modo.

Sabiéndose que el modo aplicable es la tradición, ello quiere decir entonces que la modalidad de la misma que debe utilizarse no es otra, pues, que la tradición ficta. Esto debido a que la primera y más común de las modalidades de tradición, que no es otra que la tradición real o material, no es posible aplicarla dada la naturaleza incorpórea de estos bienes, para los cuales, pues, resulta físicamente imposible entregarlos materialmente. Como se sabe, existen dos clases o modalidades de tradición: la real y la ficta.

Pero, a su vez, la tradición ficta, a diferencia de la real, reviste varias clases o modalidades. De manera que habrá que encontrar, entonces, dentro de las modalidades de tradición ficta que regula el Código Civil, una que se ajuste, pues, a este tipo de bienes y pueda servir, en consecuencia, como modo de adquisición del derecho de propiedad sobre los mismos.

Antes de iniciar el estudio de las modalidades de tradición ficta con tal objeto, es conveniente primero precisar el concepto de dicha institución jurídica. Es Ramón Badenes Ga:sset quien la define didácticamente de la siguiente manera: "La llam æda traditio ficta se da cuando la entrega de los bienes no es real o material, sino que consiste en ciertos hechos demostrativos de ella" (7).

Pues bien, la primera modalidad de tradición ficta que regula el Código Civil es la "Tradictio Brevi Manu", conocida así desde el Derecho Romano. Esta consiste o se da, como prescribe el inciso $1^{\circ} \mathrm{del}$ artículo 902 del Código Civil, cuando cambia el título posesorio de quien está poseyendo. Ramón Badenes Gasset la explica de la siguiente manera: "Tiene lugar cuando el adquirente de una cosa la

(7) BADENES GASSET, Ramón. El Contrato de Compraventa, Tomo I. Barcelona 1979, p. 485. 
tiene ya en su poder por virtud de otro título distinto, por ejemplo, el de arrendatario" (8).

Como se puede apreciar, la "Tradictio Brevi Manu" puede servir como modo de adquisición de propiedad de los muebles incorporales sólo en el caso que haya de por medio, por parte del adquirente, la posesión del mueble incorporal que se ha enajenado. Sólo en este caso en especial servirá como modo esta modalidad de tradición ficta. Por tal razón, no se puede considerar a la "Tradictio Brevi Manu" como el modo de transferencia de propiedad aplicable a los muebles incorporales, ya que dicha modalidad de tradición ficta no sirve para todas las enajenaciones, sino sólo para aquellas en las que el adquirente haya estado poseyendo el mueble incorporal que se enajena. Resulta evidente darse cuenta, pues, que no se puede aplicar como regla una excepción, por lo cual el modo de transferencia de propiedad aplicable a los muebles incorporales sólo será aquél que sirva o sea útil a todas las enajenaciones en general.

La segunda modalidad de tradición ficta que regula el Código Civil es el "Constitutum Possesorium". Al igual que la "Tradictio Brevi Manu", se encuentra regulada también en el inciso $1^{\circ}$ del artículo 902 del Código Civil. Ramón Badenes Gaset la explica, comparándola con la "Tradictio Brevi Manu", de la siguiente manera: "Se ofrece en la hipótesis contraria a la anterior, de que el dueño que enajena entre a poseerla en otro concepto, como arrendatario, depositario, etc." (9).

Se trata también, en consecuencia, de un cambio de título posesorio de quien está poseyendo; pero en este caso ya no respecto del adquirente, como se da en la "Tradictio Brevi Manu", sino respecto al transferente. Es, pues, la situación opuesta o contraria a la "Tradictio Brevi Manu". Por eso Ramón Badenes Gasset agrega, refiriéndose al caso de la compraventa, que: "El orden de los actos jurídicos exigiria que la cosa fuese transmitida al comprador y que después éste la entregase de nuevo al vendedor para que entrase a poseerla en concepto de arrendatario, depositario, etc., pero a fin de

(8) BADENES GaSSET, Ramón. Op.Cit., Tomo I, p. 498.

(9) BADENES GASSET, Ramón. Op.Cit., Tomo I, p. 498. 
evitar todo esto se supone, por una ficción de derecho, constituida la posesión a favor del comprador en virtud de la cláusula "Constitutum Possesorium" (cfr. Ley 9a. título 30, Partida 3a.)" (10).

Por lo expuesto, se debe concluir definiendo al "Constitutum Possesorium" como lo hace Manuel Antonio Laquis: "Es el caso opuesto de la "Tradictio Brevi Manu", ya que en él se trata del propietario que enajena la cosa y se constituye en tenedor o poseedor" (11).

Pues bien, como se puede apreciar, lo mismo que se concluyó para la "Tradictio Brevi Manu", para el tema bajo análisis, se debe concluir también respecto al "Constitutum Possesorium". Es decir, el "Constitutum Possesorium" puede servir como modo de adquisición de propiedad de los muebles incorporales sólo en el caso que haya de por medio, por parte del transferente ahora, la posesión del mueble incorporal que se ha enajenado. Al igual, pues, que la "Tradictio Brevi Manu", sólo en este caso en especial servirá como modo esta modalidad de tradición ficta.

Por lo tanto, por las mismas razones que para la "Tradictio Brevi Manu", no se puede considerar al "Constitutum Possesorium" como el modo de transferencia de propiedad aplicable a los muebles incorporales.

La tercera modalidad de tradición ficta que regula el Código Civil es la cesión de la acción restitutoria. Esta se da cuando, como prescribe el inciso $2^{\circ}$ del artículo 902 del Código Civil, se transfiere el bien que está en poder de un tercero. Autores alemanes como Arthur von Tuhr, Fritz Baur, Theodor Suss y Andreas Rothlisberger (12),

(10) BADENES GaSSET, Ramón. Op.Cit., Tomo I, p. 499.

(11) LAQUIS, Manuel Antonio. Derechos Reales. Tomo I, Buenos Aires 1975 , p. 394.

(12) VON TUHR, Arthur. Solicitud de propiedad en muebles de acuerdo al Código Civil Alemán comparado con el derecho del Código Civil Francés. En: Revista Puchelts para Derecho Civil Francés. Mannheim 1899, p., 535. 
son los que explican que esta modalidad de tradición ficta consiste no en otra cosa que en la cesión, del transferente al adquirente, del derecho de exigir la restitución del bien al tercero, que es quien lo está poseyendo actualmente.

Como se puede apreciar, esta modalidad de tradición ficta es propiamente una cesión de derechos. Como se sabe, la cesión de derechos es un modo de transmisión de las obligaciones y consiste, tal como lo prescribe textualmente el artículo 1206 del Código Civil, en el acto de disposición en virtud del cual el cedente trasmite al cesionario el derecho a exigir la prestación a cargo de su deudor, que se ha obligado a transferir por un título distinto. Manuel GarcíaAmigo explica acertadamente que: "... el objeto de la cesión de créditos es la titularidad activa de la relación obligatoria simple..." (13).

Esta modalidad de tradición ficta se trata, pues, de la cesión del derecho de restitución del transferente al adquirente, por encontrarse el bien en posesión de un tercero. Por tal razón, por tratarse propiamente de la cesión de un derecho y no de una acción, es más conveniente denominarla: "cesión del derecho de restitución".

Antes de determinar si esta modalidad de tradición ficta es o no el modo de transferencia de propiedad aplicable a los muebles incorporales, es conveniente precisar que el término "poder" utilizado por el inciso $2^{\circ}$ del artículo 902 del Código Civil equivale a "posesión", ya que es evidente darte cuenta que a lo que se refiere es, pues, al ejercicio de este derecho real por parte de un tercero.

Como ya es obvio advertir, con la cesión del derecho de restitu-

SUSS, Theodor. El Principio de la Tradición. Atavismo de los Derechos Reales. En Revista de Martin Wolff. Tubingen 1952, p. 152.

BAUR, Fritz. Derechos Reales. Munich 1985, p. 24.

ROTHLISBERGER, Andreas. El principio de la tradición y el principio del consenso en el acuerdo sobre muebles. Una investigación comparativa con la codificación ibérica y latinoamericana. Tesis de Doctor. Zurich 1982, p. 77.

(13) GARCIA-AMIGO, Manuel. La Cesión de Contratos en el Derecho Español. Madrid 1964, p. 81. 
ción sucede exactamente lo mismo, para el tema bajo análisis, que con las anteriores modalidades de tradición ficta ya analizadas. Es decir, al igual que con la "Tradictio Brevi Manu" y el "Constitutum Possesorium", la cesión del derecho de restitución sólo puede servir como modo de adquisición de propiedad de los muebles incorporales en el caso en que el mueble in corporal que se enajena se encuentre en posesión de un tercero. Por tal razón, tampoco se puede considerar a la cesión del derecho de restitución como el modo de transferencia de propiedad aplicable a los muebles incorporales.

La cuarta modalidad de tradición ficta que regula el Código Civil es la tradición documental o instrumental. Ramón Badenes Gasset la define de la siguiente manera: "La tradición instrumental (tradictio instrumenti o tradictio cartae) es aquélla en la que se sustituye el cambio real de posesión por la forma escrita, con entrega del documento que acredita la compra o liberalidad, o aun sin ella" (14). Consiste, como se puede apreciar, en el simbolismo de considerar entregado el bien entregando el documento que lo representa. Por tal razón, la tradición documental o instrumental es una clase 0 modalidad a su vez de la tradición simbólica.

Alfonso Barragán explica el concepto de tradición simbólica de la siguiente manera: "La tradición se califica de simbólica cuando la entrega se realiza mediante signos que la representan por así haberlo establecido la ley, con fundamento en lo que ordinariamente sucede y en la forma como las gentes proceden en la vida diaria" (15). La tradición simbólica, en consecuencia, es una modalidad de tradición ficta que reviste a su vez dos modalidades: tradición simbólica instrumental y tradición simbólica no instrumental. Sobre esta última, Ramón Badenes Gasset señala que: "Es la que se hace mediante la entrega de signos o cosas representativas de lo que se transmite (como llaves, títulos, etc.)" (16).

El Código Civil regula la tradición documental para dos supues-

(14) BADENES GASSET, Ramón. Op.Cit., Tomo I, p. 486.

(15) BARRAGAN, Alfonso. Derechos Reales. Bogotá 1971, p 422.

(16) BADENES GASSET, Ramón. Op.Cit., Tomo I, p. 495. 
tos o situaciones concretas: artículos en viaje y artículos sujetos al régimen de almacenes generales (artículo 902). En consecuencia, tampoco puede ser ésta el modo de transferencia de propiedad aplicable a los muebles incorporales porque, como es obvio darse cuenta, estas dos situaciones para las que el Código Civil regula la tradición documental sólo pueden operar para muebles corporales.

La quinta modalidad de tradición ficta que regula el Código Civil es la tradición jurídica. Esta consiste, tal como lo prescribe el artículo 1059 del Código Civil, en entender entregado el bien al acreedor cuando queda en poder del deudor. Por tal razón, el Código Civil regula esta modalidad de tradición ficta sólo para la prenda que recae sobre bienes muebles inscritos (Artículo 1059). Esto se debe a que es en este derecho real que el deudor prendario puede verse necesitado de no entregar materialmente el bien materia de la prenda, sino, por el contrario, mantenerlo en su poder debido a que con la utilización o explotación del mismo podrá pagar la obligación garantizada. Para tal eventualidad, en consecuencia, el Código Civil contempla la entrega jurídica y se evita así tener que recurrir a la figura de la prenda sin desplazamiento.

Se puede apreciar, por lo tanto, que esta modalidad de tradición ficta opera sólo en función de la transferencia de la posesión, más no en función de la transferencia de la propiedad. Por eso es que sólo resulta ser aplicable a la prenda. Por tal razón, tampoco es éste el modo de transferencia de propiedad aplicable a los muebles incorporales.

La última modalidad de tradición ficta que regula el Código Civil es la "puesta a disposición". Esta consiste en el ofrecimiento que debe practicar el deudor de un bien al acreedor del mismo para que éste último pueda recepcionarlo. Es decir, para que el acreedor del bien pueda tomar posesión del mismo, es necesario, pues, que el deudor se lo ponga a su disposición. Como se puede apreciar, se trata de un acto necesario que debe realizar el deudor, poner el bien a disposición del acreedor, para que pueda verificarse la entrega real del bien.

Sobre este ofrecimiento en que consiste la "puesta a disposición", Ernesto Wayar señala acertadamente lo siguiente: "El ofrecimiento del deudor debe traducirse en un acto real, no basta la mera 
declaración de voluntad, aunque ésta llegue a conocimiento del acreedor. Lo que interesa es que el deudor ponga a disposición del acreedor la prestación, de tal manera que sólo de éste último dependa que se consume el cumplimiento" (17). Debe consistir, en consecuencia, en un ofrecimiento real de pago de la obligación de entrega del bien por parte del deudor. Manuel Albaladejo, finalmente, define técnicamente esta modalidad de tradición ficta de la siguiente manera: "Por "puesta a disposición" en sentido estricto se entiende la dicha figura de otorgar a otro la posesión de derecho, conservando el poder de hecho el que pone la cosa a disposición de aquél" (18).

El Código Civil regula la "puesta a disposición" sólo para la transferencia del riesgo en el contrato de compraventa (artículos 1568 y 1569). Para demostrar suficientemente que el Código Civil regula la "puesta a disposición" como una modalidad de tradición ficta, es bueno y pertinente citar al legislador peruano en materia de compraventa. Manuel de la Puente y Lavalle afirma que: "Existe una discrepancia doctrinaria respecto al significado jurídico de la puesta del bien a disposición del comprador. Unos, entre los que sobresale Garrigues, sostienen que desde el punto de vista de la obligación del vendedor existe equivalencia entre entrega (artículo 1567 del Código Civil peruano de 1984) y puesta a disposición (artículo 1568 del mismo Código). Otros, a cuya cabeza se encuentra Alonso, piensan que tal equivalencia no debe existir, pues con ello se estaría dejando de proteger los intereses del comprador, anticipando el riesgo a su cargo" (19). Inmediatamente después de afirmar esto, para no dar lugar a dudas, el legislador opta acertadamente por una de estas posiciones, para lo cual afirma lo siguiente:"El artículo $1568 \mathrm{del}$ Código Civil de 1984 se inclina por la posición de Garrigues" (20).

(17) WAYAR, Ernesto. El Pago por Consignación. Buenos Aires 1983, p. 111 .

(18) AlBALADEJO, Manuel. Curso de Derecho Civil Español. Tomo III "Derecho de Bienes". Barcelona 1982, p. 104.

(19) DE LA PUENTE Y LAVALLE, Manuel. La Teoría del Riesgo en el Código Civil de 1984. En: Para Leer el Código Civil . Tomo I. Lima, 1985, p. 191.

(20) Ibidem. 
De acuerdo a la naturaleza de esta modalidad de tradición ficta, es claro apreciar que tampoco puede ser el modo de transferencia de propiedad aplicable a los muebles incorporales, por cuanto, como resulta evidente darse cuenta, sólo es posible aplicarla a los bienes corporales. En efecto, sólo es posible "poner a disposición" bienes de naturaleza corpórea, material o tangible. Física o materialmente es imposible "poner a disposición" un bien incorporal. Esto por un lado, y también porque, como ya se ha señalado, esta modalidad de tradición ficta opera sólo para la transferencia del riesgo y no para la transferencia de propiedad.

Pues bien, del análisis que se ha efectuado de todas las modalidades de tradición ficta que regula el Código Civil, se tiene que ninguna de ellas viene a ser el modo de transferencia de propiedad aplicable a los muebles incorporales.

Y no podía ser de otra forma, en realidad, por cuanto el modo de transferencia de propiedad que propiamente es aplicable a este tipo de bienes (incorporales) es la "cuasitradición", que es una modalidad de tradición ficta no regulada por el Código Civil peruano. Manuel Albaladejo define el concepto de "cuasitradición" de la siguiente manera: "Junto a la tradición, está la cuasitradición o tradición de la posesión, no de cosas, sino de derechos" (21). Igualmente, Ramón Badenes Gasset señala respecto de la cuasitradición que: "Se llama así a la tradición aplicada a las cosas incorporales o derechos" (22).

Es el Código Civil español el que regula claramente a la "cuasitradición", de la siguiente manera:

Artículo 1464 .- Respecto de los bienes incorporales, regirá lo dispuesto en el párrafo segundo del artículo 1462. En cualquier otro caso en que éste no tenga aplicación, se entenderá por entrega el hecho de poner en poder del comprador los títulos de pertenencia, o el uso que haga de su derecho el mismo comprador consintiéndolo el vendedor.

(21) ALBALADEJO, Manuel. Op.Cit., p. 105.

BADENES GASSET, Ramón. Op.Cit., Tomo I, p. 499. 
Artículo 1462 .- Se entenderá entregada la cosa vendida cuando se ponga en poder y posesión del comprador.

Cuando se haga la venta mediante escritura pública, el otorgamiento de ésta equivaldrá a la entrega de la cosa objeto del contrato, si de la misma escritura no resultare 0 se dedujere claramente lo contrario.

Sobre lo dispuesto por estas dos normas, Ramón Badenes Gasset señala lo siguiente: "El Código dedica a las cosas incorporales el artículo 1464 y aparte de la forma general, consistente en el otorgamiento de la escritura pública, precisa el precepto dos formas especiales de entrega de los bienes incorporales" (23). Para luego seguir afirmando: "La tradición que se realiza en los llamados bienes incorporales, por equivalencia a la quasi possesio es denominada cuasi tradición, pudiendo consistir en el traspaso de los títulos (simbólica) o en el uso de los derechos enajenados que evidencia y realza la intención del comprador, a ciencia y paciencia del vendedor (por ministerio de la Ley)" (24).

Cabe aquí discrepar con Ramón Badenes Gasset; la cuasitradición, en realidad, tal como está regulada en el Código Civil español, sólo consiste en el simple otorgamiento de la escritura pública. Es decir, el otorgamiento de la escritura pública equivale a entrega (artículo $14622^{\circ}$ párrafo, C.C. español), y no es ésta una forma general de cuasitradición, habiendo también dos formas especiales de la misma como señala este autor. Por cuanto la tradición que opera en defecto de escritura pública, es decir, cuando no hay de por medio este documento, es la tradición simbólica instrumental (artículo 1464 C.C. español); la cual es, como ya se ha visto, una modalidad distinta de tradición ficta. Por tal razón, si se aceptara lo conceptuado por Ramón Badenes Gasset, se estaría concluyendo que la cuasitradición es también tradición simbólica instrumental, con lo cual la cuasitradición no tendría sentido o utilidad como figura o modalidad propia de tradición ficta.

La cuasitradición, en consecuencia, consiste en considerar en-

(23) BADENES GASSET, Ramón. Op.Cit. Tomo I, p. 499.

(24) Ibidem. 
tregado el bien incorporal con el simple otorgamiento de la escritura pública. Esto quiere decir que cuando en el acto jurídico dispositivo no hay de por medio este documento, no podrá haber cuasitradición, sino que en este supuesto habrá que recurrir a otra modalidad de tradición ficta como es la tradición simbólica instrumental.

Pues bien, al legislador peruano se le olvidó, entonces, incorporar en el Código Civil la cuasitradición, con lo cual hubiese quedado propiamente cubierto el modo de transferencia de propiedad aplicable a los muebles incorporales. Digo "propiamente" por cuanto, obviamente, el hecho de esta omisión legislativa no puede conducir a concluir que no sea posible transferir la propiedad de esta clase de bienes. Como se está frente a un vacío legal, se debe recurrir entonces a la aplicación analógica de la ley. Mediante ello se podrá encontrar, pues, un modo de transferencia de propiedad aplicable a este tipo de bienes; el cual será, no un modo directo, sino por extensión o analogia.

Lo que se debe hacer, en consecuencia, es encontrar, de todas las modalidades de tradición ficta que regula el Código Civil, una que se pueda ajustar a este tipo de bienes (incorporales), y poderla aplicar analógicamente a los mismos.

Así, se tiene que, de todas las modalidades de tradición ficta que regula el Código Civil, es la tradición simbólica instrumental la única que se puede ajustar como modo de transferencia de propiedad aplicable a los muebles incorporales. Esto lo demuestra plenamente el Código Civil español, al prescribir en el artículo 1464 que, en defecto de que no pueda aplicarse la cuasitradición (cuando no haya otorgamiento de escritura pública), se entenderá por entrega el hecho de poner en poder del comprador los títulos de pertenencia. Es de notar, claro está, que en el Código Civil Español no se necesita recurrir a la analogía para poder aplicar la tradición simbólica instrumental a los bienes incorporales, sino que ésta resulta aplicable directamente por haber una norma en dicho Código que así lo establece expresamente.

La tradición simbólica instrumental, llamada también "tradición documental" simplemente, se ajusta perfectamente para los muebles incorporales. Es decir, sí se puede aplicar perfectamente esta modalidad de tradición ficta para este tipo de bienes. 
Además de para los casos de artículos en viaje o sujetos al régimen de almacenes generales (artículo 903), el Código Civil regula la tradición documental también para la compraventa sobre documentos (artículo 1580). Aplicando entonces analógicamente estas normas, se tiene finalmente que, en el Código Civil peruano, el modo de transferencia de propiedad aplicable a los muebles incorporales es la tradición documental.

Para poder transferir el derecho de propiedad de los muebles incorporales, como una marca o una patente, por ejemplo, se deberá hacer entrega, pues, de algún documento que represente el bien 0 que acredite la transferencia del mismo. En este caso, si ha habido de por medio escritura pública, se transferirá la propiedad del mueble incorporal con la entrega de dicho documento al adquirente. Y si no hubo de por medio escritura pública, la propiedad de este bien se transferirá con la entrega de los títulos o documentos que representan al bien $o$ acreditan la titularidad del mismo.

\section{CONCLUSIONES}

1) El Código Civil peruano no regula el modo de transferencia de propiedad aplicable a los bienes muebles incorporales.

2) El modo de transferencia de propiedad que "propiamente" es aplicable a los muebles incorporales, es la "cuasitradición".

3) El Código Civil peruano no regula a la "cuasitradición".

4) La "cuasitradición" es la tradición aplicable sólo a los bienes incorporales. Consiste en considerar entregado el bien incorporal con el simple otorgamiento de la escritura pública que acredita el título dispositivo.

5) En el Código Civil peruano, por analogía, el modo de transferencia de propiedad aplicable a los muebles incorporales resulta ser la "tradición documental". 